medical ethics in this book. A useful bibliography is appended. J.J.B.

\section{RADIOLOGICAL PHYSICS}

By M. E. J. Young, M.Sc. Pp. $x+365$, with 184 illustrations. London: H. K. Lewis \& Co. Ltd. I $957.42 \mathrm{~s}$.

This book is designed to meet the requirements of students working for the diplomas in radiology of the Royal College of Physicians of London and the Royal College of Surgeons of England, or for membership or fellowship of the Society of Radiographers. It does so admirably.

A knowledge of elementary physics is assumed, but two helpful introductory chapters deal with fundamental concepts of modern physics and with electronic valves respectively. This material should complete very adequately the background of the average student before he commences to read the book proper.

The book is comprehensive and deals lucidly with the physical properties and measurement of ionizing radiations, their biological and chemical effects, and their use in diagnostic and therapeutic radiology. An up-to-date account is given of the use of artificial radioactive isotopes in medicine, and of radiological protection. The approach is a very practical one showing an insight into everyday clinical problems; for example, the discussion of treatment planning in X-ray therapy would prove most helpful to a radiographer. All students will appreciate the inclusion of recent examination questions at the end of each chapter, and those who wish to delve deeper will find invaluable the lists of references to original papers and to books for further reading. The book would provide an excellent introduction to the subject for physicists just starting hospital work.

It cannot be too highly recommended.

\section{PRACTICAL ELECTROCARDIOGRAPHY}

By Henry J. L. Marriott, M.D. Second Edition. Pp. $x v+226$, with 158 illustrations. London: Baillière, Tindall \& Cox Ltd. I 957. 40s.

The second edition of this concise little book is even more lavishly illustrated than the first, and contains some useful additions to the text. The relationship of events occurring in the heart to the shape of the complexes seen in the various leadsparticularly the anatomical and positional aspects of this relationship-are not always made sufficiently clear. But the book is otherwise excellent, and its printing and layout remain superb.

\section{RECENT ADVANCES IN UROLOGY}

By Howard G. Hanley, M.D., F.R.C.S. London: J. \& A. Churchill Ltd. I 957.30 .

This book is written with a refreshing economy of descriptive style, that is the more commendable since five contributors support the author in giving a survey of recent advances in urology. The result is a short and lucid text that contrives to sketch a clear outline of the common problems of urological practice, and to give a wise review of their management. Reference is made throughout to contributory work on which present views are based.

The opening chapter gives a valuable account of renal function and a practical guide to the treatment of its derangement. The chemotherapy of urinary infections is then discussed, with comment on the nature and action of those agents in common use. A chapter on radiological methods emphasizes the scope offered by the image amplifier. Thereafter the surgical advances of recent years are presented with adequate descriptions of operative technique and balanced views on the clinical indications for their employment. The one topical trend that is not mentioned is the increased interest in external urethrotomy for stricture that has been stimulated by the satisfactory results of Johanson's operation. In a critical search for omissions it is possible also to cite Goodwin's concept of transluminal ureterosigmoidostomy, though this procedure has not excited the interest which it appears to deserve in this country, and this book is professedly not a review of recent literature. It is a practical guide written from experience, enhanced by well-chosen references to relevant sources, and as such must commend itself to the postgraduate student.

J:P.H.

\section{HORMONAL REGULATION OF ENERGY METABOLISM}

Edited by L. W. Kinsell, M.D. Pp. xiii +242 . Oxford: Blackwell Scientific Publications. I 957. 40 .

This is in the nature of a colloquium organized by a programme committee consisting of Drs. Kinsell, Finch, Friskey, Griffith, Luetscher and Madden. Many other men prominent in endocrinological and biochemical research attended and an attempt to summarize the present position in relation to hormonal regulation and enzymatic interrelations in the field of carbohydrate metabolism, pituitary thyroid and adrenal cortical function was made.

The book makes interesting reading, but one feels that its main value was for the participants, since a great deal has been left out and a lot that is included comes into the category of interesting speculation.

\section{AN INTERNATIONAL SYMPOSIUM ON ALDOSTERONE}

Edited by Alex F. Muller, M.D., and Cecilia M. O'Connor, B.Sc. Pp. $\mathrm{x}+232$, with 84 illustrations. London: J. \& A. Churchill Ltd. I 958. $40 s$.

In June I 957 a symposium was held in Geneva devoted to the subject of aldosterone and organized 